\title{
ist \\ Mundo da vida e racionalidade científica
}

\author{
Marcus SAGRINI
}

\begin{abstract}
曲
RESUMO

Este artigo explora alguns aspectos da noção de "mundo da vida" apresentada por Edmund Husserl, de modo a contribuir com o desenvolvimento do modelo da interação entre ciência e valores proposto por Hugh Lacey. Em particular, almeja-se mostrar a fundação das estratégias descontextualizadoras de pesquisa científica nas experiências concretas, compostas de diversos níveis de operações intencionais.
\end{abstract}

PaLAVRAS-Ghave $\bullet$ Mundo da vida. Horizonte. Intencionalidade. Estratégias descontextualizadoras.

As considerações contidas neste texto pretendem servir para o desenvolvimento do modelo geral de inter-relações entre a ciência e os valores proposto por Hugh Lacey em várias obras. As relações que tenho em vista são aquelas entre alguns momentos constituintes da atividade científica e os valores sociais ou mesmo as próprias circunstâncias concretas dos contextos sociais em que a ciência é desenvolvida. Lacey e Mariconda (2014) distinguem diferentes momentos ou etapas na atividade científica. Haveria um momento teórico central no qual hipóteses ou teorias são avaliadas à luz de critérios e valores puramente cognitivos. E em torno dessa avaliação cognitiva, haveria várias etapas em que claramente valores e demandas sociais tomam parte na condução da atividade científica, tais como, por exemplo, a etapa de seleção de fenômenos considerados importantes para serem pesquisados ou a etapa de implementação de aplicações tecnológicas do conhecimento obtido. Torna-se, desse modo, explícito que os contextos sociais em que o processo científico está inserido são condicionantes da quase totalidade desse processo. Minha intenção é explorar conceitualmente esses contextos que excedem o núcleo estritamente cognitivo da obtenção do conhecimento, a fim de explicitar algumas consequências filosóficas da constatação de que a atividade científica sempre se desenvolve em meio a demandas e valores sociais. Para tanto, vou servir-me da noção de "mundo da vida" para caracterizar essas dimensões extrateóricas sem as quais a produção do conhecimento científico não se completaria. 
Sem dúvida, como se verá, a noção de "mundo da vida" envolve muito mais as pectos conceituais do que a simples consideração de que em alguns pontos-chave da prática científica ocorrem relações com "grupos sociais" ou mesmo "sociedades". Acredito que a riqueza conceitual contida nessa noção permite agregar ganhos teóricos importantes ao modelo proposto por Lacey. Para tornar visíveis esses ganhos, pretendo desenvolver uma pesquisa mais abrangente sobre o tema, que apenas se inicia neste texto. Na exposição que se seguirá, almejo somente circunscrever o conteúdo conceitual dessa noção e apontar a sua função filosófica geral em relação ao modelo proposto por Lacey. Em outros textos, planejo analisar ao menos dois pontos mais específicos referentes às interações entre as ciências e o mundo da vida, a saber, o papel deste último como "fundamento movente" do conhecimento e, em segundo lugar, as tensões entre a relatividade cultural-axiológica componente do mundo da vida e a objetividade científica. Quanto ao primeiro ponto, trata-se de esclarecer que, enquanto solo de sentido para a atividade científica, o mundo da vida não deve ser tomado como um núcleo de propriedades fixas que garantiria unilateralmente a validade dos resultados teóricos, o que não passaria de uma variante das concepções fundacionistas clássicas. $\mathrm{O}$ mundo da vida é o mundo da experiência concreta dos sujeitos históricos, e a experiência desses sujeitos tem sido cada vez mais modificada pela inserção constante de inovações tecnológicas de grande impacto nas mais diferentes áreas da vida (comunicação, saúde, transporte etc.). Dessa forma, o mundo da vida oferece a base para o desenvolvimento da ciência mas, por sua vez, esta última transforma o próprio mundo da vida do qual partiu. A tematização dessas relações circulares pode ajudar a compreender os pressupostos que sustentam a quase hegemonia das estratégias descontextualizadoras na atividade científica contemporânea. Quanto ao segundo ponto, trata-se de explicitar a multiplicidade de perspectivas valorativas que compõem a experiência do mundo da vida e questionar de que forma elas podem contribuir para uma compreensão racional abrangente da realidade.

Essas são as direções que serão tomadas pela pesquisa. Por ora, gostaria somente de expor os principais elementos conceituais da noção de mundo da vida.

Meu ponto de partida para explorar essa noção é a obra de Edmund Husserl (18591938), fundador da fenomenologia, doutrina filosófica que propõe, grosso modo, a suspensão da validade do caráter objetivo, efetivo (ou, nas palavras do autor, da "posição de ser") daquilo que aparece na experiência para justamente considerar essa experiência em seu puro aparecer fenomenal, livre das interpretações ontológicas cotidia- 
namente atribuídas àquilo que nela se manifesta. Após suspender a validade de ser da experiência, realizando, então, a "redução fenomenológica", o fenomenólogo busca tematizar as operações subjetivas que constituem em diversos estratos os diferentes tipos de sentido (perceptivo, afetivo, cultural, etc.) em vigor nessa mesma experiência (cf. Husserl, 2006, §27-32; 86).

Esse projeto filosófico envolve inúmeros pressupostos cuja discussão foge ao escopo deste artigo. Importa notar que, em grande medida, Husserl desenvolveu a noção de “mundo da vida” em análises filosóficas pré-fenomenológicas, ou seja, que não supõem ainda os recursos conceituais e metodológicos voltados para a descrição do puro aparecer fenomenal. Na verdade, a noção de "mundo da vida" serve como uma via introdutória para a redução fenomenológica (cf. Husserl, 2012, §43); dessa maneira, é possível retomar alguns componentes dessa noção sem comprometer-se com as complexas etapas de instauração da orientação fenomenológico-transcendental do (ato de) pensar. Além disso, cabe notar que outros autores (por exemplo, Patocka, Schütz e Habermas) serviram-se da noção de "mundo da vida" de modo bastante frutífero, e haveria aqui, sem dúvida, à luz da obra desses autores, possibilidades bem diferentes de explorá-la. Independentemente da fecundidade desses caminhos possíveis, pretendo concentrar-me somente em algumas considerações husserlianas sobre o mundo da vida.

Por meio da ideia de "mundo da vida", Husserl procura explicitar a experiência ou vivência concreta (sem distinção entre esses termos) na qual as pessoas estão cotidianamente inseridas. De modo geral, essa experiência cotidiana apresenta um mundo ambiente (Umwelt) comum, vivido em uma pluralidade de sentidos entrelaçados que constituem, em grande medida passivamente, um pano de fundo global sobre os quais se desenrolam os projetos pessoais e interpessoais. Por exemplo, o entorno cotidiano é formado por muitas outras pessoas, além de variados tipos de objetos (em sentido amplo) materiais percebidos: prédios, postes elétricos, ruas, árvores, automóveis, aparelhos de TV, rios, computadores conectados em rede etc. Esses objetos são passíveis de subsunção a diferentes categorias (naturais, artificiais e híbridas, o que pode envolver objetos naturais modificados por intervenção tecnológica - represas, transgênicos etc. - ou mesmo objetos artificiais moldados por meio de processos naturais computação biomolecular etc.); no entanto, comumente são experimentados conforme certos parâmetros histórico-culturais gerais de utilidade, beleza, eficácia etc. Dessa maneira, na experiência comum do mundo da vida, os objetos não são catalogados por um olhar teórico supostamente desengajado das circunstâncias culturais-valorativas, mas imediatamente apreendidos conforme teias de sentido mais ou menos estáveis, transmitidas no correr das gerações. 
É importante acentuar, neste ponto, que o mundo é vivido como diretamente acessível às capacidades dos sujeitos encarnados. Trata-se, assim, do mundo que se doa constantemente à intuição subjetiva, formando um solo de evidências originárias sobre as quais as práticas discursivas se desenvolvem. Além disso, trata-se também do meio em que se desenvolvem cotidianamente essas práticas discursivas; o mundo da vida envolve a sedimentação de sentidos socioculturais pelos quais os sujeitos se reconhecem e interagem conforme os contextos e instituições sociais no interior dos quais são formados e em relação aos quais desenvolvem seus projetos pessoais e interpessoais; projetos que podem almejar inclusive modificar certos aspectos desses contextos e instituições (cf. Husserl, 2012, §36).

Como se vê, a noção de "mundo da vida" sugere um amplo pano de fundo, constituído de atividades perceptivas e de interações linguístico-culturais, que está pressuposto no desenrolar das atividades sociais particulares. A fim de tornar mais claros os temas aí presentes, vale a pena explorar o sentido dos próprios termos que compõem essa noção. Inicialmente, enfatizemos a "vida" na expressão "mundo da vida". Tentase aqui capturar o mundo tal qual vivido subjetiva e intersubjetivamente. A expressão "mundo da vida" sempre remete às experiências que apreendem o mundo e, em sentido geral, por meio dela tenta-se caracterizar o mundo enquanto doado aos sujeitos e não como infraestrutura objetiva independente das capacidades subjetivas.

Importa acentuar um aspecto central dessa referência constitutiva do mundo à subjetividade. $O$ mundo da vida é o mundo tal como experimentado pelos diversos tipos de atos intencionais, estratificados na elaboração das experiências comuns vividas pelas pessoas concretas. ${ }^{\mathbf{A}}$ A experiência cotidiana envolve sínteses perceptivo-motoras anônimas ou pré-subjetivas que mantêm ordenados os campos de dados conscientes mais básicos, mas também envolve tomadas de posições deliberadas, em que atuam as capacidades eminentemente subjetivas (escolha de um fim, seleção de meios etc.). Deve-se notar, assim, que há constantemente riqueza ou densidade dos conteúdos intencionais apreendidos na experiência do mundo. Daí que o "mundo" seja o correlato da "vida", noção esta que exprime aqui não um conjunto de funções fisiológicas, mas a unidade sinérgica de diversos níveis de produção de sentido, conforme a atuação das intencionalidades perceptivas, afetivas, linguísticas, empáticas, estéticas etc. O mundo da experiência concreta é vivido na complexidade de interações simultâneas de várias ca-

1 Entende-se por atos intencionais as vivências subjetivas enquanto estruturalmente direcionadas para algo. Tratadas como atos intencionais, as vivências não são consideradas como estados mentais isolados, mas justamente como correlações entre um polo subjetivo e um polo objetivo ao qual sempre se está voltado (por exemplo, uma percepção não é um episódio mental fechado em si mesmo, mas a experiência de algo percebido). Desse ponto de vista, as experiências vividas sempre se ordenam de maneira significativa conforme as particularidades das modalidades intencionais subjetivas na apreensão ou expressão de seus temas ou polos objetivos (cf. Husserl, 2006, §36, 84). 
pacidades intencionais. Ele não é somente o mundo da percepção ou o mundo das regras sociais, já que esses títulos remetem a atividades subjetivas e intersubjetivas parciais, e justamente o que se tenta capturar com a expressão "mundo da vida" são as vivências em que diversos tipos de funções ou capacidades intencionais atuam simultaneamente para apresentar o mundo circundante repleto de sentidos em diferentes níveis.

Quanto agora ao outro termo componente da expressão "mundo da vida", a saber, "mundo", não se trata de apontar para a totalidade das coisas existentes ou mesmo para o planeta Terra. Não é nesse sentido que se utiliza a expressão "mundo da vida". Conforme já mencionado, o que se tem em vista é o mundo tal como vivenciado pelas pessoas concretas. Dessa maneira, muito mais do que um conjunto de coisas ou um tipo de ente, o termo "mundo" indica uma certa estrutura de organização das experiências. E qual é essa estrutura de experiências que reconhecemos como "mundo"? Husserl fala em síntese entre dados particulares e horizontes de sentido (cf. Husserl, 2012, apênd. XVIII). Aideia que se tenta exprimir aqui é a seguinte: as experiências particulares sempre se desenrolam em uma sucessão de fases parciais que se sintetizam, apresentando paulatinamente o sentido da situação então vivida. Essa síntese não se dá meramente pela justaposição de momentos discretos, mas pela referência dos dados parciais a horizontes de sentido no interior dos quais as experiências se desenrolam. Isso quer dizer que as experiências vividas não se esgotam em seus aspectos singulares, mas sempre remetem a campos amplos de sentido nos quais os dados parciais estão inseridos (cf. Husserl, 2006, §35). A percepção de uma coisa espacial envolve a copercepção do ambiente em que essa coisa está localizada; a produção de um discurso envolve referências aos modos como as significações são usadas pela comunidade linguística; o agir social ocorre à luz de regras partilhadas acerca do que é permitido ou proibido. Essa remissão dos conteúdos particulares a horizontes de sentido não funciona apenas como contextualização de todo dado particular em um campo pré-ordenado. Sem dúvida, esse seria o aspecto mais diretamente reconhecível das estruturas de horizonte de toda vivência intencional. Mas, além disso, essa estrutura realiza um papel prescritivo em relação às experiências particulares. Desse ponto de vista, importa salientar que as experiências particulares não decorrem de maneira aleatória ou apenas conforme as conexões intrínsecas dos dados singulares em pauta, mas se organizam segundo certas antecipações de sentido em vigor nos horizontes nos quais se inserem. A percepção de um objeto desconhecido, por exemplo, desenrolar-se-á em conformidade com as expectativas avançadas pelo horizonte de perceptibilidade no qual o sujeito se encontra. Assim, quando se trata de um objeto tridimensional, há a expectativa de que esse objeto possua vários lados acessíveis por diferentes perspectivas etc. De modo similar, a relação com uma pessoa desconhecida tende a seguir as prescrições típicas do comportar-se em situações semelhantes àquela atualmente vivenciada, e assim por diante. 
Esse caráter antecipatório da progressão das experiências conforme horizontes gerais de sentido é central na constituição do mundo da vida. Por meio dessa estrutura, o que se deixa entrever é uma totalidade coerente de eventos a serem vivenciados conforme as possibilidades sugeridas pelos horizontes de sentido. $O$ mundo é, assim, vivido em uma certa expectativa de sentido coeso, vivido segundo uma tendência estrutural da experiência de ordenar a multiplicidade de eventos particulares em um todo unitário (ainda que estratificado) de sentido. ${ }^{2}$ As vivências particulares são unificadas em referência a horizontes amplos de sentido, que prefiguram o curso da experiência daquilo que ainda não se doou diretamente, daquilo que excede as fronteiras do ambiente familiar, mas que já é minimamente antecipado como parte de um só e mesmo mundo, cujos parâmetros de sentido se estendem, então, para muito além dos dados parciais atualmente confrontados.

Não se deve pensar que essa estrutura de horizonte funciona como uma espécie de determinação rígida para as experiências particulares. É verdade que na maior parte dos casos ela funciona como pressuposto com base no qual se podem resolver conflitos interpretativos entre as experiências particulares. Na maioria das vezes, por exemplo, uma percepção que não se encaixa no fluxo coeso da exploração perceptiva de um ambiente não destrói esse fluxo, mas justamente é revelada como errônea à luz da continuação coerente da progressão perceptiva. A atestação do engano perceptivo particular supõe a continuidade do processo perceptivo global segundo o horizonte sedimentado de perceptibilidade. Cabe enfatizar, contudo, que algumas vezes os conflitos nas experiências particulares podem levar a alterações no sentido global veiculado pelo horizonte. Essas modificações amplas são mais prováveis no que tange às relações intersubjetivas, que também ocorrem sob horizontes de sentido que prefiguram cursos mais ou menos coerentes para as situações particulares. Os horizontes de sentido das ações sociais envolvem perspectivas valorativas e mesmo sistemas de crenças ordenadas por vezes em complexas visões de mundo. Ocorrem aqui com frequência conflitos

2 Para uma exposição mais detalhada desse tema, seria preciso especificar as particularidades das expectativas de coerência em relação às capacidades intencionais em ação. Parece que os níveis pré-subjetivos de ordenação da experiência (as sínteses perceptivas e motoras) lançam expectativas de coerência bastante rígidas, cujo rompimento marca justamente a não efetuação correta ou normal dessa capacidade subjetiva (por exemplo, uma miragem rompe a expectativa de continuidade do curso perceptivo em um deserto; mas trata-se justamente de um episódio anômalo que pode ser excluído da síntese perceptiva normal que se prefigurava em uma progressão contínua). Já nos níveis que envolvem deliberação subjetiva e intersubjetiva, as expectativas de coerência são mais frouxas, uma vez que as possiblidades de continuidade dos cursos das ações são muito mais complexas (por exemplo, no embate de grupos políticos em sociedades democráticas, muitas ações podem até ser caracterizadas como incoerentes em certo cenário, sem que com isso sejam consideradas um mero episódio anômalo a ser excluído de uma suposta progressão contínua claramente delineada). Por sua vez, isso permitirá que haja mais mudanças dos componentes centrais dos próprios horizontes de expectativas desses níveis ativos que daqueles pré-subjetivos, conforme discutirei a seguir neste artigo. 
devidos às relatividades culturais-valorativas referentes a interpretações dos fatos e a modos de agir. Muitas vezes, por meio desses conflitos altera-se, em parte, a própria estrutura de horizonte com base na qual se apreende o desenrolar dos eventos particulares. Uma seita religiosa fiel à figura do seu líder carismático pode desfazer-se diante de provas convincentes de que se tratava de um charlatão. E esse evento particular, o desmascaramento de um líder desonesto, implica mudanças amplas na compreensão do sentido dos eventos cotidianos para os membros: arrefecimento do pensamento mágico, solidificação da verificação empírica como critério para a recusa de certas previsões etc. Assim, critérios amplos para a atribuição de sentido são alteráveis diante de evidências no âmbito das experiências particulares.

Note-se que essa alteração ocorre em favor da manutenção de um alto grau de coerência global das vivências, em favor da unificação do fluxo contínuo de experiências em um só mundo, cujos parâmetros de sentido são lançados para toda a experiência futura. Seguindo o exemplo, o líder religioso pode ter sido desmascarado por propor um código de conduta ao qual ele mesmo não se submeteu, por fazer previsões que não se concretizaram, por apresentar como milagres o que não passava de truques de mágica. Em quaisquer desses casos, prevalece a manutenção da coerência na apreensão das experiências. Preceitos gerais que não se sustentam diante de evidências imediatas tendem, assim, a ser abandonados. E obviamente deixar-se guiar por evidências imediatas supõe, por sua vez, submeter-se a novos horizontes amplos de sentido, em relação aos quais tais evidências justamente se ordenam. Dessa maneira, a mudança de certos componentes do horizonte de sentido se dá em favor de outros componentes que se impõem como mais eficazes na antecipação daquilo que compõe o mundo.

O mundo é, então, experimentado como um conjunto de experiências que tende à unificação coerente em horizontes antecipadores de sentido, os quais, até certo ponto, são passíveis de alteração. O mundo concretamente vivido não é, nessa concepção, um conjunto fixo de entes ou significações que predeterminam univocamente o curso das vivências. Há uma estrutura fundante - vivências particulares/horizontes de sentido -, a qual, entretanto, é móvel em seus conteúdos, aberta para modificações ou correções. ${ }^{3}$ Essa mobilidade dos conteúdos dos horizontes mundanos torna compreensíveis ao menos algumas das relatividades culturais, já que diferentes parâmetros antecipatórios interpretativos das experiências particulares são mais ou menos compatíveis com essas experiências. No entanto, conforme revela o exemplo do líder religioso, há a possibilidade de reconfigurar as prescrições gerais tornando-as mais

3 Em outro texto pretendo considerar de que maneira essa mobilidade da estrutura do mundo diante de conflitos interpretativos da experiência permite lançar luz sobre as perspectivas viáveis de valores e sua relação com a produção da objetividade científica. 
abrangentes e resistentes à variedade das situações concretas. Para Husserl, uma das principais virtudes do conhecimento científico seria a capacidade de explicitar, por meio de métodos e recursos teóricos de grande precisão, algumas das estruturas mais gerais de horizonte que delimitam as possibilidades do desenrolar da experiência para além das relatividades culturais exprimidas em diferentes visões de mundo (cf. Husserl, 2012, §36). Não pretendo discutir essa pretensa virtude do conhecimento científico, mas sim um dos seus efeitos colaterais, por assim dizer, o fato de que a produção de conhecimento por meio de certo tipo de estratégia apaga a importância do mundo da vida na formulação desse próprio conhecimento.

Vimos que por meio da noção de "mundo da vida", tenta-se expressar a riqueza intencional da experiência concreta em seu desenrolar típico, conforme os horizontes de sentido em vigor. Quero ressaltar agora que essa riqueza intencional opera como um pressuposto sobre o qual a atividade científica se desenvolve. De uma forma inicialmente óbvia, a ciência pode ser descrita, em termos muito gerais, como uma atividade coletiva entre outras no mundo da vida, ou seja, uma atividade realizada por pessoas concretas inseridas em comunidades especializadas, historicamente desenvolvidas e ordenadas conforme certas regras partilhadas e legadas às gerações seguintes. Nesse sentido, a atividade científica pressupõe constantemente o mundo da vida como horizonte geral de sentido que contextualiza e prescreve o curso de inúmeras práticas particulares por meio das quais a ciência é produzida (por exemplo, as práticas de interações linguísticas regidas por normas racionais, tais como antecipar objeções, defender uma tese etc.; voltarei a esse tema) (cf. Husserl, 2012, §34f).

Além disso, a referência ao mundo da vida permite lançar nova luz a alguns dos aspectos específicos da atividade científica. Parece que toda investigação científica ocorre por meio de uma correlação entre certa orientação do pensar/agir e um domínio a ser investigado. A orientação em pauta aqui é a teórica, a qual se compõe de um conjunto de métodos tendo em vista a explicitação dos componentes e relações constituintes de um campo temático. $\mathrm{Na}$ orientação teórica, em geral, há um desinteresse metódico por muitos dos atributos dos fenômenos investigados. Mencionei que o mundo da vida é experimentado concretamente como um correlato intencional denso da vida subjetiva, ou seja, é experimentado por meio de uma multiplicidade de apreensões de sentidos que atuam sinergicamente. A orientação teórica se demarca dessa experiência concreta do mundo por minimizar voluntariamente a importância de muitos desses sentidos que compõem os fenômenos concretos e, assim, isolar somente 
certos aspectos em relação aos quais se busca entendimento de seus elementos e relações constituintes. Os atributos estéticos, práticos, valorativos com que normalmente os fenômenos concretos se apresentam são por assim dizer suspensos para que o investigador exerça apenas uma apreensão puramente cognitiva dos objetos visados. ${ }^{4}$ E em correlação com essa minimização inicial dos interesses práticos, estéticos etc., o campo para o qual se volta a orientação teórica é composto por aspectos artificialmente isolados. Trata-se de um domínio objetivo, enquanto resultado da explicitação metódica de características descritíveis por meio dos métodos em vigor na orientação teórica assumida. A objetividade é aqui associada tanto à exclusão dos atributos ligados à atividade produtora subjetiva (qualidades estéticas, práticas, morais) quanto à explicitação correta das relações naturais, por assim dizer, entre os componentes puramente materiais do domínio em vista, relações que ocorreriam independentemente das valorações e preocupações cotidianas dos sujeitos (cf. Husserl, 1952, cap. 1).5

Desse modo, a ciência é uma prática entre outras no interior do mundo da vida, mas com uma particularidade notável: ela constitui domínios objetivos particulares por meio de uma orientação específica do pensar, neutralizadora de grande parte da riqueza da vida intencional que continuamente enforma os fenômenos vividos. Um tema que se abre agora para análise é aquele das relações entre a racionalidade em vigor nos métodos especificamente cognitivos, que permitem a delimitação desses domínios objetivos, e as práticas intencionalmente densas do mundo da vida. O processo científico de isolamento de dados constituintes dos domínios objetivos envolve o uso especializado de certos esquemas metódicos para a obtenção de dados e análise de resultados. Dessa maneira, a orientação teórica na qual o conhecimento é produzido serve-se de alguns recursos lógicos e experimentais na construção do conhecimento objetivo. Delineiam-se, assim, os contornos de uma racionalidade estrita, compreendida como a aplicação metódica de técnicas para a obtenção de dados e a avaliação de hipóteses e teorias. ${ }^{6}$ Fixam-se procedimentos típicos para a produção de resultados

4. Refiro-me aqui aos momentos de aplicação dos métodos científicos, nos quais se busca pautar-se por critérios ou valores puramente cognitivos (cf. Lacey \& Mariconda, 2014). Porém, conforme o modelo de Lacey torna visível, antes de chegar a esse ponto, vários interesses não puramente cognitivos tomaram parte na decisão de investigar certo grupo de fenômenos em detrimento de outros, tais como interesses práticos, já que uma das grandes motivações para a investigação de certos fenômenos é a expectativa de extrair aplicações tecnológicas de grande impacto social.

5 Pelo menos essa parece a noção de objetividade vigente nas estratégias descontextualizadoras de pesquisa científica, as quais comentarei no decorrer do texto.

6 Não defendo que toda a racionalidade científica reduz-se a essa aplicação metódica. Pelo contrário, o que tentarei mostrar é que não há racionalidade científica plenamente autônoma nesse sentido. Em todo caso, é preciso reconhecer que os recursos lógicos e experimentais utilizados pelas ciências por vezes envolvem grande complexidade e variedade, cabendo à teoria do conhecimento explicitá-los e discutir seu alcance e limitações. 
justificados à luz da correta aplicação dos passos metódicos previstos pela estratégia adotada. Agir racionalmente, nesse sentido estrito, é saber seguir corretamente esses passos metódicos.

Esse uso de esquemas teóricos especializados é muito eficiente na produção de resultados legítimos no interior de certas estratégias científicas. Mas dificilmente esses esquemas se sustentariam por si sós, sem referências constantes a práticas racionais amplas, não especializadas (práticas desenvolvidas normalmente nas interações linguísticas pré ou extracientíficas no mundo da vida), e sem as quais a aplicação dos procedimentos metódicos estritos dificilmente avançaria. Por exemplo, o uso adequado de métodos para a obtenção de dados supõe seja discussões acerca do escopo temático a ser abarcado, seja avaliação constante da pertinência da metodologia para o caso em questão; a formulação de hipóteses para a análise dos dados supõe uma inventividade que muitas vezes não é abarcada pelos passos rígidos das metodologias teóricas; a apreciação dos resultados obtidos supõe a capacidade de antecipar e responder a objeções; o reconhecimento de possíveis falhas nos procedimentos supõe uma retomada reflexiva do trabalho realizado. Em todos esses casos, a racionalidade estrita dos métodos teóricos especializados remete constantemente a capacidades racionais amplas utilizadas em inúmeros contextos intencionais no mundo da vida (familiares, políticos, jurídicos etc.). Por conseguinte, a aplicação satisfatória das estratégias ou metodologias fixas depende de interações linguísticas extracientíficas como suporte para a obtenção de teses cientificamente aceitáveis. ${ }^{7}$

Ocorre que certas estratégias científicas dificultam o reconhecimento do caráter fundante dessas interações mundanas em seus contextos intencionais densos para a própria prática científica. É o caso das estratégias descontextualizadoras, que buscam isolar a infraestrutura material dos fenômenos investigados, a fim de produzir teorias explicativas, baseadas em leis acerca dos seus componentes e nas relações vigentes entre eles (cf. Lacey \& Mariconda, 2014). Essas estratégias permitem a circunscrição de domínios objetivos altamente especializados, cujos componentes materiais só podem ser identificados pela utilização de recursos técnicos muitas vezes de grande complexida-

\footnotetext{
${ }_{7}$ Essa conclusão revela que não só nas etapas iniciais e finais da atividade científica (por exemplo, seleção de fenômenos e métodos, e extração de inovações tecnológicas) elementos extracientíficos estão essencialmente presentes na condução dessa atividade. Mesmo na etapa de avaliação cognitiva das hipóteses ou teorias, os recursos extracientíficos do mundo da vida devem atuar para que os critérios cognitivos sejam aplicados de modo satisfatório. Não se trata aqui de esvaziar a objetividade do conhecimento científico, de reduzi-la a relações sociais e de poder etc. Trata-se simplesmente de reconhecer que mesmo a avaliação teórica por meio de critérios cognitivos é uma prática cumprida por pessoas inseridas no mundo da vida, e não por supostos puros sujeitos cognitivos, que exerceriam seu olhar teórico independentemente de quaisquer restrições mundanas. Isso não significa, entretanto, que não haja um tipo específico de validade objetiva, a teórica, que só pode ser obtida pelo uso correto dos critérios cognitivos e não por decisões políticas, por exemplo.
} 
de, seja no nível da linguagem lógico-matemática, seja no nível da instrumentação laboratorial requerida (considere-se, por exemplo, o domínio do genoma humano ou das partículas subatômicas). A especialização dos recursos metodológicos para a circunscrição dos domínios objetivos descontextualizados é acompanhada pela neutralização da maior parte dos conteúdos intencionais por meio dos quais as pessoas experimentam os fenômenos mundanos. O domínio objetivo circunscrito pelas estratégias descontextualizadoras não se doa à intuição imediatamente partilhável pelos sujeitos perceptivos, não envolve nenhum predicado valorativo ou estético, não se presta por si só a nenhuma finalidade prática particular. Grande parte da riqueza da experiência intencional mundana pré-científica é, assim, suspensa para que se desvelem as relações naturais entre os componentes materiais dos fenômenos.

Deve-se notar que a pretensão de validade dos resultados objetivos descontextualizados em relação à experiência mundana pré-científica normalmente é de fundação ontológica. Aquilo que é objetivo, enquanto domínio de relações entre os componentes materiais regido por leis naturais, é apresentado como uma camada de ser básica, sobre a qual se desenvolvem os diversos níveis da experiência concreta mundana. Desse modo, as estratégias descontextualizadoras reconduziriam a riqueza das vivências intencionais nas quais o mundo da vida se manifesta a camadas de interações objetivas naturais: primeiramente a camada do mundo físico ou físico-químico (a constituição da matéria, seus componentes e relações), em seguida, a camada da vida orgânica (compreendida em termos dos processos biológicos para a manutenção da homeostase, processos em tese redutíveis às relações físico-químicas), por fim, a camada dos eventos psíquicos (compreendida com base nos correlatos neurais que sustentariam a variedade das experiências subjetivas). Desse ponto de vista, toda a riqueza da experiência do mundo da vida poderia ser reduzida a representações psíquicas derivadas do substrato neural, o qual, por sua vez, seria regido por regularidades biológicas, as quais, ao menos em tese, poderiam ser remetidas a interações físico - químicas da natureza material. Dessa forma, atestar-se-ia a fundação ontológica do mundo da vida nos domínios objetivos circunscritos pelas estratégias descontextualizadoras.

Apresento aqui de maneira muito superficial um amplo escopo de aplicação das estratégias descontextualizadoras, que engloba as áreas de atuação das ciências físicas, biológicas e psicológicas, em uma perspectiva reducionista. Sem dúvida, haveria muito a ser discutido acerca da viabilidade teórica dessa perspectiva e mesmo se ela está ou não necessariamente ligada às estratégias descontextualizadoras. Importa somente salientar que por meio dessas estratégias os fenômenos densos do mundo da vida são decompostos em camadas de eventos objetivos, os quais, por sua vez, são tomados como ontologicamente fundantes das vivências subjetivas. Porém, para que esse programa de fundação possa mesmo fazer sentido, pressupõe-se o tempo todo uma outra ordem de 
fundação, uma fundação, por assim dizer, hermenêutica, que remete a aplicação metódica das estratégias descontextualizadoras e a avaliação dos seus resultados às práticas e evidências pré e extracientíficas do mundo da vida. Afinal, como vimos, a aplicação correta e a avaliação convincente dos resultados obtidos pelas estratégias descontextualizadoras depende de interações racionais que não fazem parte, de modo especializado, dos passos metódicos rígidos dessas estratégias, interações racionais que constituem, ao menos em parte, as experiências intersubjetivas no mundo da vida.

Os resultados das estratégias descontextualizadoras podem ser discutidos à luz de objeções possíveis, a delimitação dos dados pode ser questionada à luz de novas considerações relevantes e coerentes e, em suma, a atividade científica supõe constantemente relações comunicativas baseadas em normas racionais. ${ }^{\mathbf{8}}$ Contudo, normas racionais não são dados objetivos obtidos pela aplicação das estratégias descontextualizadoras. As normas fazem parte do conjunto de vivências intencionais que são justamente neutralizadas para que a especificidade das relações entre os componentes materiais dos domínios objetivos seja explicitada. As normas racionais não são objetos dos domínios circunscritos pelas estratégias descontextualizadoras; elas não integram, assim, as camadas ontologicamente fundantes da experiência subjetiva, as quais seriam compostas de eventos puramente naturais. Na verdade, o que se sugere em certos contextos de aplicação dessas estratégias é que as normas racionais poderiam ser redutíveis aos domínios objetivos. Essa é a imagem sugerida, por exemplo, por estudos psicofísicos descontextualizados, que reconduzem a variedade das relações intersubjetivas a interações causais no substrato cerebral de cada indivíduo. Nesse caso, as normas racionais reconhecidas em interações linguísticas seriam decompostas em relações causais fundadas no substrato corporal objetivamente considerado.

Ora, o que vale para a racionalidade científica em geral também vale nesse caso: para o estabelecimento dessa ordem de fundação objetiva descontextualizada (as relações causais no substrato cerebral), supõem-se as interações comunicativas entre os cientistas, os quais, ao discutirem a correção de seus resultados, não tratam seus colegas como sujeitos psicofísicos condicionados pelo substrato cerebral, mas dirigem-se a eles como indivíduos guiados por normas racionais e sociais, pessoas com as quais se busca formar um consenso justificado acerca de certas hipóteses ou teses. Dessa forma, a experiência comunicativa baseada em razões não figura como objeto nos domínios circunscritos pelas estratégias descontextualizadoras e, no entanto, a obtenção de resultados válidos nesses domínios supõe a comunicação normativa no interior da comunidade científica. Daí que seja necessário reconhecer o papel fundante das práticas

8 Discutir com mais detalhes como as normas racionais atuam nos contextos densos do mundo da vida excede o escopo deste artigo. 
do mundo da vida em relação aos domínios objetivos descontextualizados. A circunscrição e validação dos resultados referentes a tais domínios não são compreensíveis somente conforme as categorias de objetos explicitados como seus componentes (cf. Scanlon, 1996). Por exemplo, as normas racionais não aparecem como parte dos domínios objetivos obtidos por aplicação das estratégias descontextualizadoras para entender a vida psíquica. Esta última é reconduzida, segundo tais estratégias, aos correlatos neurais e suas interações causais, as quais são apresentadas como ontologicamente fundantes das normas racionais (compreendidas então como um tipo de conteúdo representacional psíquico). No entanto, as normas racionais atuam como condicionantes da constituição da objetividade científica, já que esta última só pode ser estabelecida por meio de discussões racionalmente guiadas. Desse ponto de vista, aquilo que era secundário ou fundado pelos entes do domínio objetivo descontextualizado é, na verdade, fundante desse próprio domínio. Há, assim, um papel preponderante das práticas pré-científicas no mundo da vida, em particular da comunicação regida por razões, em relação à objetividade construída pela aplicação das estratégias descontextualizadoras.

\section{IV}

Retomo os principais resultados obtidos pela exposição acima. A noção de "mundo da vida" busca capturar a experiência concreta em toda a sua riqueza intencional. $\mathrm{O}$ mundo enquanto vivido concretamente envolve as capacidades gestuais, perceptivas, linguísticas, afetivas e empáticas dos sujeitos inseridos simultaneamente em diversos contextos de interações. Com base nessa noção, é possível compreender as ciências, em termos gerais, como fruto da sedimentação histórica de um desses contextos, quer dizer, como um conjunto de práticas normativas sedimentadas por comunidades que herdaram procedimentos e resultados, desenvolvem-nos e legam novas aquisições teóricas e técnicas para gerações futuras. E enquanto interagem nesses contextos normativos, os cientistas servem-se das experiências intencionalmente densas do cotidiano para estabelecer suas teses teóricas. Essa constatação, por sua vez, lança questões críticas sobre o alcance das estratégias descontextualizadoras. Como vimos, a delimitação de domínios objetivos especializados depende das interações linguísticas racionais em vigência na experiência concreta. Esse condicionamento da obtenção da objetividade descontextualizada pela normatividade presente nas interações intencionais cotidianas é um tema que pode contribuir para o desenvolvimento do modelo proposto por Lacey. Afinal, esse modelo tenta justamente explicitar e discutir as diferentes relações entre a atividade científica e alguns dos componentes (em particular, os 
valores sociais) das vivências intencionais concretas. E a tematização do mundo da vida como horizonte geral em que a prática científica se desenrola auxilia a tornar visíveis os papéis dessas vivências na produção do conhecimento objetivo..

Marcus SAGRInI

Departamento de Filosofia, Universidade de São Paulo, Brasil.

sacrini@usp.br

\title{
Lifeworld and scientific rationality
}

\begin{abstract}
This article explores some aspects of the notion of "lifeworld", presented by Edmund Husserl, in order to contribute with the development of Hugh Lacey's model of the interaction between science and values. Particularly, one aims at showing the foundation of decontextualized strategies of scientific research in the concrete experiences, which are compounded of several layers of intentional activities.
\end{abstract}

KEYWords $\bullet$ Lifeworld. Horizon. Intentionality. Decontextualized strategies.

\section{REFERÊNGIAS BIBLIOGRÁFICAS}

Husserd, E. Ideen zu einer reinen Phänomenologie und phänomenologischen Philosophie. Zweites Buch. Haag: Martinus Nijjhof, 1952 .

. Ideias para uma fenomenologia pura e uma filosofia fenomenológica. Tradução M. Suzuki. Aparecida: Ideias \& Letras, 2006.

. A crise das ciências europeias e a fenomenologia transcendental. Tradução D. F. Ferrer. São Paulo: Forense Universitária, 2012.

Lacey, H. \& Mariconda, P. O modelo das interações entre as atividades científicas e os valores, Scientiae Studia, 12, 4, p. 64,3-68, 2014.

Nenon, T. \& Embree, L. (Ed.). Issues in Husserl's Ideas II. New York: Springer, 1996.

Scanlon, J. Objectivity and introjection in Ideas II. In: Nenon, T. \& Embree, L. (Ed.). Issues in Husserl's Ideas II. New York: Springer, 1996. p. 213-22. 